\title{
Numerical Analysis of the Core Dimensions of a Magnetic Fault Current Limiter Assuming a Practical Design and Trial Production
}

\author{
H. Nakamichi, K.Yotsutsuji, S. Yamada, and M. Iwahara \\ Graduate School of Natural Science and Technology, Kanazawa University, Kakuma machi, Kanazawa 920-1192, Japan
}

\begin{abstract}
Recently, current suppression devices such as fault current limiters (FCLs) have been required to reduce excessive currents in power distribution lines when the short-circuits occur in the expanding electric power systems, which have high impedance in the fault condition and the low impedance in the normal condition. To realize the required operation, the dc magnetization point of magnetic fault current limiters must be designed to lie in the saturation region under normal conditions. Since a the magnetic FCL is characterized by a dc magnetization point, which depends on the shape of the magnetic core and the magnetic properties, numerical analysis was performed and experimental discussions were held to establish a design procedure for FCLs.
\end{abstract}

Key words: magnetic FCL, magnetic circuit, dc magnetization point, equivalent permeability

\section{実用設計を想定した磁気式限流器磁心寸法の数值解析とその試作}

中道勇人・四辻和也・山田外史・岩原正吉

金沢大学自然科学研究科，石川県金沢市角間町（广920-1192）

\section{1. はじめに}

現代技術の電気への依存性はますます高まっており，電 力需要は今後も高まることが予想される，その結果，万一 電力系統に故障が発生すると, 大きな短絡, 地絡電流が流 れ，甚大な被害を系統にもたらしかねない。これに対し， 電力系統ではこのような故障電流から電力系統を保護し, かつ事故の広範囲な拡大を防止する方法として各種の保護 機能が準備されている 1),2). 故障電流を極力小さくすること ができれば，各種の被害を低減できるばかりでなく，系統 運用の面において系統安定度の向上や瞬時電圧低下の抑制 効果にも役立つなど大きな利点を有する。また，故障対策 だけではなく老朽機器の延命や遮断器の短絡容量低減の点 で有効であり, 電力自由化による本格的な価格競争や設備 投資の低下によるコスト削減方法としても有用である。そ こで, 電力用各種故障電流抑制用限流器(FCL : Fault Current Limiter)の開発・実用化が望まれており研究され ている ${ }^{3,4)}$.

これまで磁気式限流器について $\mathrm{E}$ 型巻鉄心を想定し, 限流 率に基づきその最適形状が検討されている5). 本文では数 $\mathrm{kVA}$ 程度の配電向け磁気式限流器を実用化するに当たり, その設計手順確立のために必要な直流偏磁点と磁心寸法の 関係を調べ，更に等価インダクタンスを用いた数值計算に よる検討を行い, 実際に装置を試作し検討をする.

\section{2. 磁気式限流器の動作原理と直流偏磁点}

限流器は Fig.1 のように回路に挿入され Fig.2 のような 特性を持つことが求められる. すなわち, Fig.2 中の限流開 始電流 I linek 以下では低インピーダンスで電圧降下は小さ く, 電流の抑制はほとんどなく, 限流開始電流以上では高 インピーダンスで電圧降下が大きくなり電流が抑制される. 磁気式限流器では, 通常動作時は磁心の磁気特性の飽和域
が低インピーダンスであることを利用し，故障時（大電流 時）は不飽和域が高インピーダンスであることを利用して 動作させる 5).

対象とする磁気式限流器は Fig.3 に示す形状の磁心中央 脚に永久磁石を挿入し構成される複合型磁心の左右脚に巻 線を巻いた構造をしており，この複合型磁心の動作点 5)は Fig.4のように永久磁石の磁気特性（線形近似）と磁心の全 体的な磁気特性（折れ線近似）の交点となるが，磁気式限 流器は巻線下で動作することを考慮すると動作点である直 流偏磁点は Fig.4 で示されるP点となる，然るに，装置は この直流偏磁点 $\mathrm{P}$ を心に動作することから, 磁気式限流 器の設計に強く影響する。そこで，限流器の設計仕様を念 頭においた磁心と永久磁石の形状及び直流偏磁点との関係 を明らかにしておく必要がある。

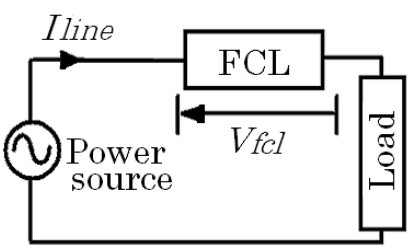

Fig. 1 FCL in a power distribution circuit.

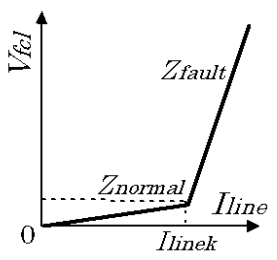

Fig. 2 Required characteristics of a FCL.

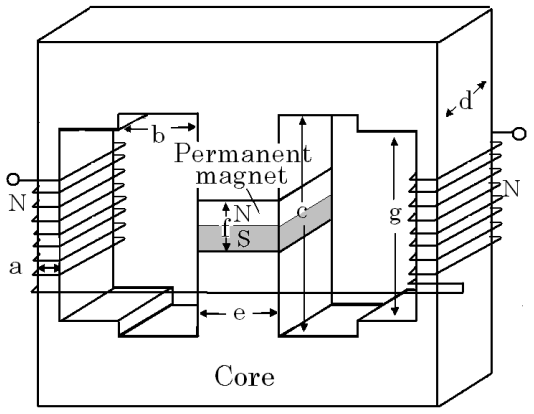

Fig. 3 Shape of a FCL 


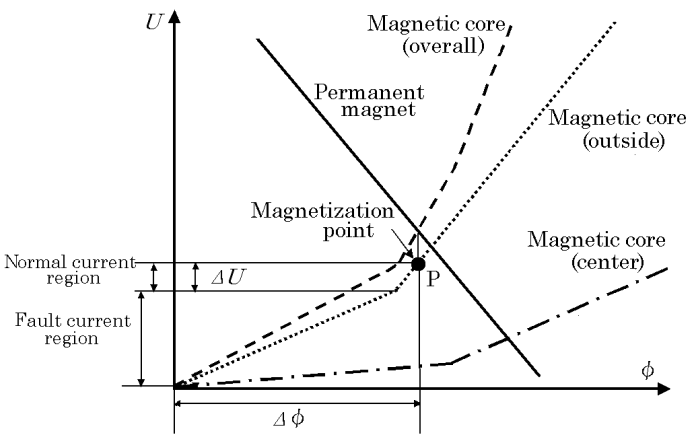

Fig. 4 DC magnetization point.

\section{3. 数值解析と磁心形状の検討}

\section{1 磁心寸法比と直流偏磁点}

磁気式限流器の左右脚は Fig.3 のように左右対称で同 一構造であり, 中央脚に磁束 $\Phi_{\mathrm{c}}$ が流れるとする時の各部の 回路方程式は次のようになる。

[永久磁石]

$$
U_{i m}=U_{m}-R_{m} \phi_{c} \text {. }
$$

$U_{m}$ :永久磁石起磁力, $R_{\mathrm{m}}$ :永久磁石の磁気抵抗 [磁心中央脚]

$$
\left.\begin{array}{l}
U_{i c}=R_{c s}\left(\phi_{c}-\phi_{k}\right)-R_{c u} \phi_{k} ; \phi_{k} \leq \phi_{c} \\
U_{i c}=R_{c u} \phi_{c} ; \phi_{c} \leq\left|\phi_{k}\right|
\end{array}\right\}
$$

$R_{\mathrm{cs}}:$ 飽和時中央脚磁気抵抗,

$R_{\mathrm{cu}}$ :不飽和時中央脚磁気抵抗, $\phi_{\mathrm{k}}$ : 磁心の飽和磁束 [磁心左右脚 $]$

$$
\left.\begin{array}{l}
U_{i p}=R_{p s}\left(\phi_{y}-\phi_{k}\right)+R_{p u} \phi_{k} ; \phi_{k} \leq \phi_{y} \\
U_{i p}=R_{p u} \phi_{y} ; \phi_{y} \leq\left|\phi_{k}\right| \\
U_{i p}=R_{p s}\left(\phi_{y}+\phi_{k}\right)-R_{p u} \phi_{k} ; \phi_{y} \leq-\phi_{k}
\end{array}\right\}
$$

$R_{\mathrm{ps}}$ :不飽和時左右脚磁気抵抗,

$R_{\mathrm{pu}}$ :不飽和時左右脚磁気抵抗, $\phi_{\mathrm{k}}$ : 左右脚の磁束

と表され，これらの式から得られる直流偏磁点の検討を行 う。また，検討に当たり，直流偏磁点の適否を判断する必 要がある. Fig.4 中の $\Delta \phi$ と最大限流器電圧 $V_{\mathrm{fclm}}$ は

$$
V_{f c l m}=N \omega \Delta \phi / \sqrt{2} \text {. }
$$

である．ただし，Nは巻数， $\omega$ は角周波数である。(4)式よ り $\Delta \phi$ が大きくなると限流器電圧が大きくなることから限 流効果も向上寸る。また $\Delta U$ と限流器を含む回路の回路電 流 $I_{\text {line }}$ は

$$
N I_{\text {line }}=\Delta U / \sqrt{2} \text {. }
$$

となる，その上で，(1)〜(3)式より直流偏磁点を求め，限流 器の端子電圧，電流を求める。一方，解析時には，Table 1 に定義する Fig.3 に対応した磁心寸法比を用いる. 数值解 析で実際に用いた基準值は Table2 の值を使用し，永久磁 石及び磁心の材料パラメータは Table3 の值を使用した。

Table 1 Definition of core dimension ratios.

\begin{tabular}{|c|c|c|c|c|c|}
\hline$\tau$ & $\alpha$ & $\beta$ & $\gamma$ & $\zeta$ & $\chi$ \\
\hline e/a & b/e & c/e & d/e & f/c & g/c \\
\hline
\end{tabular}

Table 2 Example of core dimension ratios.

\begin{tabular}{|c|c|c|c|c|c|c|}
\hline$a(\mathrm{~mm})$ & $\tau$ & $\alpha$ & $\beta$ & $\gamma$ & $\zeta$ & $\chi$ \\
\hline 7.63 & 4 & 1 & 2.67 & 1.64 & 0.24 & 0.82 \\
\hline
\end{tabular}

Table 3 Material parameters.

(a)Permanent magnet

(b) Magnetic core

\begin{tabular}{|c|c|}
\hline $\mathrm{Hc}(\mathrm{kA} / \mathrm{m})$ & 955 \\
\hline $\mathrm{Br}(\mathrm{T})$ & 1.28 \\
\hline
\end{tabular}

\begin{tabular}{|c|c|}
\hline $\mathrm{Bk}(\mathrm{T})$ & 1.8 \\
\hline$\mu \mathrm{ru}$ & 8500 \\
\hline$\mu \mathrm{rs}$ & 85 \\
\hline
\end{tabular}

a) 寸法比 $\tau$

寸法比 $\tau$ を変化させ, 断面積比を検討した結果より Fig.5 に示されるように $\tau=2.5$ 程度が必要である.また $\tau$ を大き くすることで $\Delta \phi, \Delta U$ ともに大きくなる.

b) 寸法a

磁心の大きさに直接関係する寸法 $a$ が大きくなると，磁 心が大きくなるため $\Delta \phi, \Delta U$ ともに大きくなる

c） 寸法比 $\alpha$

寸法比 $\alpha$ は磁心の空幅の寸法比であり，空幅が影響寸る 磁心部の磁心幅は中中央脚と同じことからは飽和状態にな ることはなく，特性に与える影響は極めて小さい.

d） 寸法比 $\beta$

寸法比 $\beta$ は磁心の空高さに関する寸法比であり, Fig.6よ り， $\beta$ を大きくすることで $\Delta U$ オみが大きくなることがわ かる. 寸なわち, 設計の際に直流偏磁点の $\Delta U$ の值を調整 寸るには, 寸法比 $\beta$ を変化させる（磁心の左右脚の磁路長 を大きくすること）ことが有効である.

e) 寸法比 $\gamma$

寸法比 $\gamma$ は磁心の厚さ関する寸法比であり，Fig.7より， $\gamma$ を大きくすると $\Delta \phi$ のみが大きくなることがわかる。す なわち, 設計の際に直流偏磁点の $\Delta \phi$ の值を調整するには, 寸法比 $\gamma$ を変化させる（磁心の断面積を大きくすること） ことが有効である。

f) 寸法比 $\zeta$

寸法比 とは磁石幅に関する寸法比であり，(1)式の永久磁 石の特性と(2)式の中央脚の特性に影響するが，(1)式のUお よび $R_{\mathrm{m}}$ とに関係してくるので影響は小さく，また中央脚 特性も $\alpha$ の時と同様断面積の関係から飽和領域に達せず影 響は小さい.

g) 寸法比 $x$

寸法比 $x$ は左右脚の削り高さに関する寸法比であり，(3) 式が左右脚の特性に影響するため， $\chi$ を大きくすることで

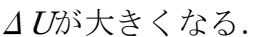

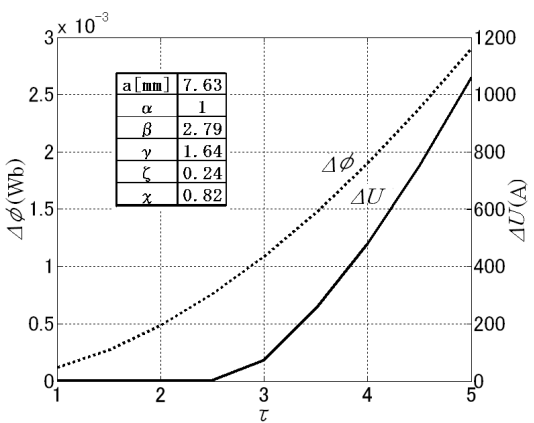

Fig. 5 DC magnetization points for varying $\tau$. 


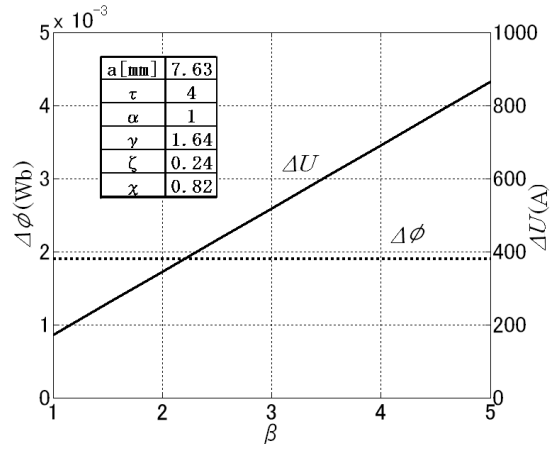

Fig. 6 DC magnetization points for varying $\beta$.

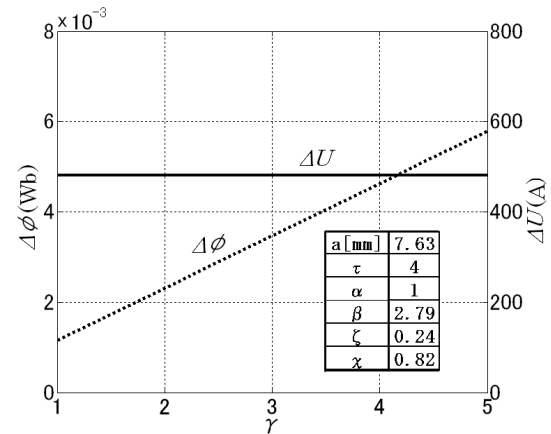

Fig. 7 DC magnetization points for varying $\gamma$.

\section{2 設計に要する等価インダクタンス}

限流器の見かけの透磁率である等価透磁率の検討を行う。 限流器の等価インダクタンスを次のように定義する. $L_{e q}=V_{f c l} / \omega I_{\text {line }}$.

ここで，式(6)中の限流器における限流器電圧 $V_{f c l}$ と回路 電流 $I_{\text {line }}$ の波形を近似的に検討寸る. 回路電流 $I_{\text {line }}$ の予想波 形はFig.8のように限流特性に合わせて限流開始電流 $I_{\text {linek }}$ 以下(破線)では電流波形に変化は無く, I linek 超える (実線) と超えた領域が抑制される. 次に限流器電圧 $V_{\mathrm{fcl}}$ の予想波形 は，Fig.9のように限流領域 $\left(\theta_{\mathrm{k}}<\theta<\pi-\theta_{\mathrm{k}}\right)$ では高イン ピーダンス時の電圧降下（ $\left.V_{\text {fclf }}\right)$ となり，非限流領域 $(\theta<$ $\left.\theta_{\mathrm{k}}, \pi-\theta_{\mathrm{k}}<\theta\right)$ では低インピーダンス時の電圧降下 $\left(V_{\mathrm{fcln}}\right)$ となる.これらの予想波形を用いて $(6)$ 式の等価インダ クタンス $L_{\mathrm{eq}}$ を導出すると次のようになる.

$L_{\text {eqs }}=\sqrt{\frac{1}{\pi}\left\{\pi-2 \theta_{k}+\sin \left(2 \theta_{k}\right)\right\}}\left(L_{u}-L_{s}\right) \cdot$

$L_{\mathrm{s}}$ :不飽和時インダクタンス, $L_{\mathrm{u}}:$ 飽和時インダクタンス

この式を用いることで等価インダクタンスと限流開始電 流から得られる $\theta_{\mathrm{k}}$ から $L_{\mathrm{s}}, L_{\mathrm{u}}$ が求まり, さらに断面積, 磁路長及び巻数から飽和時透磁率 $\mu \mathrm{s}$, 不飽和時透磁率 $\mu \mathrm{u}$ が求まる. これらの值と磁心材料の磁気特性を合わせるこ とで磁心材料を決定できる.

また限流器がどのように動作するかを知る上で(7)式を 用いて計算を行った結果を Fig10 に示す．縦軸には等価透 磁率 $L_{\mathrm{eq}}$ を不飽和時透磁率 $L u$ で割ったもの, 横軸には $と$ と して最大值電流 $I_{\mathrm{m}}$ を限流開始電流 $I_{\text {linek }}$ で割ったものを用 いた。この結果を用いることでインダクタンスがどの程度 になるかをそれぞれの值から予測できる.

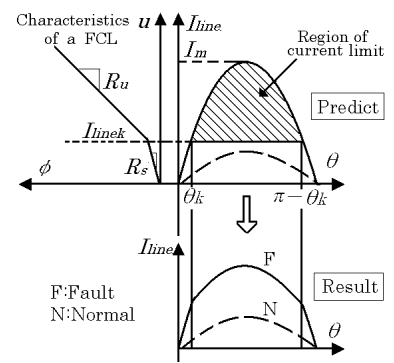

Fig. 8 Waveforms of the circuit current.

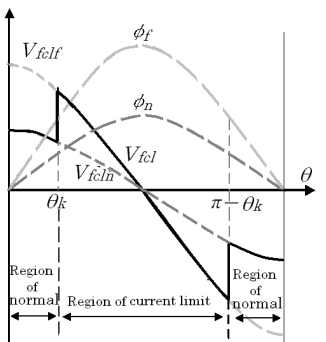

Fig. 9 Waveforms of the FCL terminal voltage.

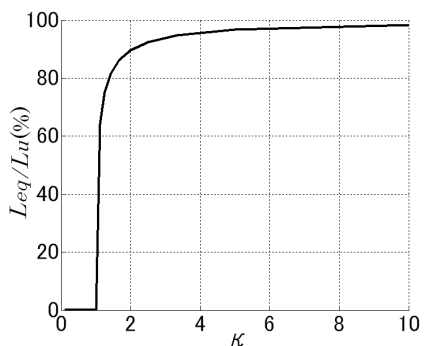

Fig. 10 Characteristic of equivalent permeability.

\section{4. 装置の試作と測定結果}

得られた数值解析の結果に基づき，数 $\mathrm{A}$ で動作するよ うな Fig.11 に示す形状の磁心を作成し（左右脚を内側から $3 / 4$ 削ったもので数值解析の基準パラメータと同じ），こ れを用いて限流器を試作し，Fig.12に示す回路で測定を行 った。また，限流器のインダクタンスを考慮して電源電圧 $V_{\mathrm{s}}=30 \mathrm{~V}$, 周波数 $f=60 \mathrm{~Hz}$ とした. 限流器は磁心の飽和領 域で動作するため負担すべき電圧及び巻線抵抗を考慮し巻 数 $N$ は片側 150 ターンとした. これらの数值から直流偏 磁点を計算すると， Fig.13 のようになり $\Delta U=480, \Delta \phi$ $=0.0019$ となる. ここで巻数は 300 ターンであるため限流 開始電流は $1.4 \mathrm{~A}$ 程度と予測される。

次に限流特性の測定結果を Fig. 14 に示寸. 得られた限流 特性は想定した通りとなった。

また，限流器の限流率入を

$\lambda=I_{\text {nonfcl }} / I_{\text {withfcl }}$.

と定義する．ここで，Inonfcl は限流器無しの場合の回路電 流， $I_{\text {withfcl }}$ は限流器有りの場合の回路電流である.

その結果を Fig.15 に示す。得られた結果より，5A 程度 で入が 2 近くまで達していることから限流器として動作し ていることがわかる．ここで，数值解析の開始電流より上 が限流領域であり，限流器がスロースタート型であること から, 限流特性上では数值解析の值より少し後で特性の折 れ点が見られる。また，限流率特性上では $1.5 \mathrm{~A}$ 程度増加傾 向が見られ，数值解析の結果とも一致する.

通常時の各部の波形，故障時の波形を Fig.16, Fig.17 に 示した。通常時の場合限流器の有無に関わらず電流の值が ほぼ等しく，限流器電圧も大きくない。一方，故障時にな ると限流器を挿入することで電流の最大值が約半分となっ ており，更に限流器電圧も予測通りの波形でかつ振幅も大 きいことから望ましい動作をしていることがわかる。 


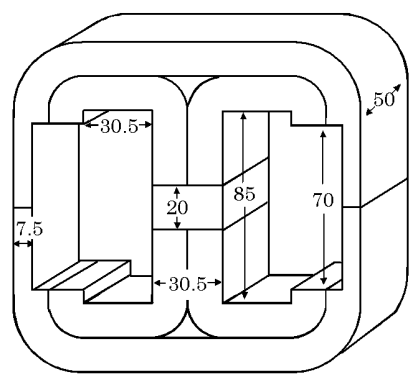

Fig. 11 FCL core for the experiment.

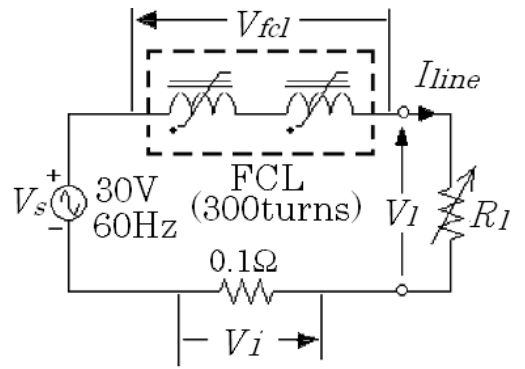

Fig. 12 Measurement circuit.

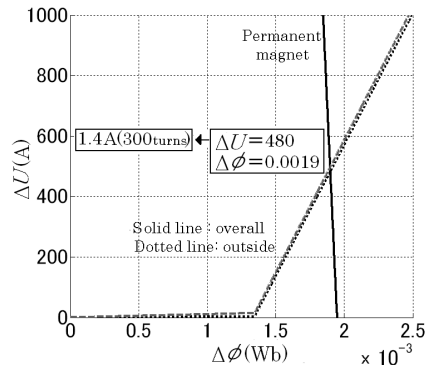

Fig. 13 DC magnetization points.

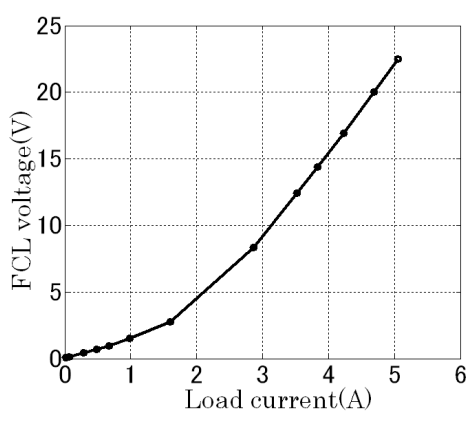

Fig. 14 Characteristics of the FCL.

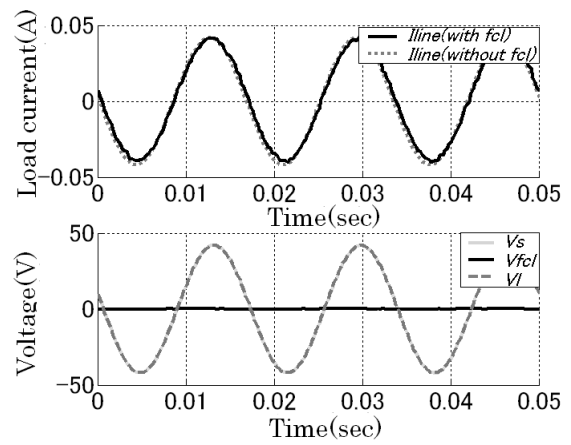

Fig. 16 Waveforms of the FCL in the normal condition.

\section{5. まとめ}

数值解析により磁気式限流器の磁心寸法比及び各種磁 気特性パラメータが直流偏磁点に与える影響を調べ，どの 寸法比を変化させることで設計仕様を満足する直流偏磁 点が得られるかを明らかにした。また，等価透磁率が各パ ラメータとどのように関係するかを調べ，等価透磁率を用 いることで材料の選定及び限流器がどのような動作とな るか明らかにした. その後, 数值解析の結果を利用して試 作限流器を作成し評価を行った. その結果, 限流特性は予 測通りの限流特性が得られることが明らかになり，限流率 として使用可能な現実的值まで達しているものが実現で きた. 加えて, 数值解析の結果から予測した值と作成した 装置から得られた実験值がほぼ等しく数值解析の有効性 が示された。

現在限流器としての容量が小さく, 所要電圧より低い電 圧でしか動作しないので, 今後は, 所要の限流特性を実現 するにあたり限流器自体のインダクタンスを大きくする ため磁心の左右脚の断面積を確保することが最も重要で あり，そのためには直流偏磁点と寸法比の検討からもわか

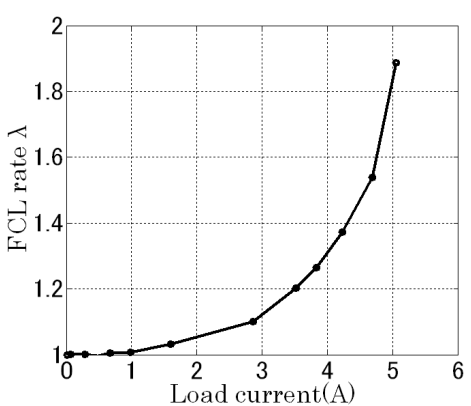

Fig. 15 Characteristics of the FCL rate.

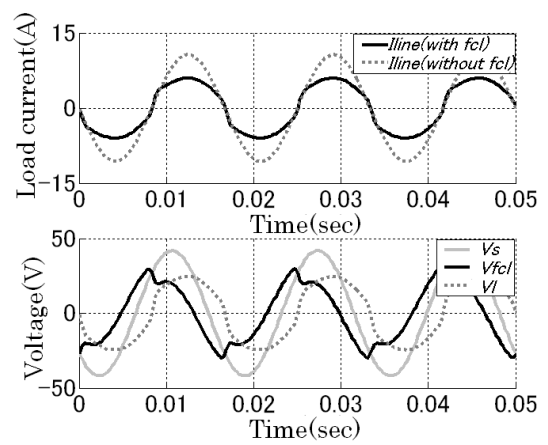

Fig. 17 Waveforms of the FCL in the fault condition.

るように磁心の脚幅と奥行き寸法を大きくとることが課 題となる.

謝辞 終わりに，本研究は(株)日立製作所にご協力戴きま した.ここに記して深謝致します.

\section{References}

1) Standstill device technology committee of IEEJ Trans. Power and Energy: Present Conditions and Prospects of Fault Current Limiting Technology, Technology report of IEEJ, No.850 (2001)

2) H.Shimizu: Current State and Trends of Fault Current Limiting Technology, IEEJ Trans. Power and Energy, No.125 (2005)

3) Michael Steurer, Klaus Frohlich : CURRENT LIMITERS STATE OF THE ART, Conference on EHV Tech(1998).

4) N.Engelman,E.Seherurs, and B.Drugge: Field Test Result for a Multishort $12.47 \mathrm{kV}$ Fault Current Limiter,IEEE Trans.PowerDlivety. Vll.6 No.3, pp.1081-1086 (1991)

5) M.Shima,S.C.Mukhopadhyay,M.Iwahara,S.Yamada: Analysis about Characteristics of Fault Current Limiter Using E type core, Trans.Magn.Soc.Jpn, Vol. 24,No.4-2, pp.811-814(2000)

\section{5年10月19日受理，2006年1月16日採録}

